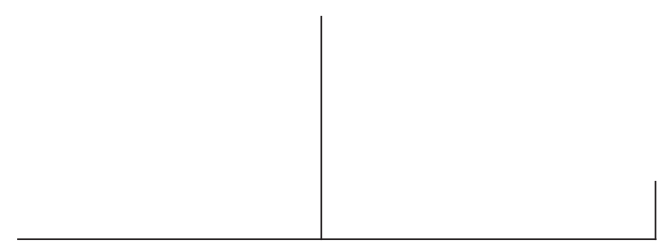

Rev. Latinoam. Psicop. Fund., II, 3, 109-123

\title{
La huída en la obra de Mario Vargas Llosa
}

\author{
German Arce Ross
}

Se trata de poner en perspectiva la mayor parte de novelas de Mario Vargas Llosa en función del tema de la huída, partiendo del hecho que él solicitó la nacionalidad Española inmediatamente después de haber perdido las elecciones para la Presidencia del Perú y de haber escrito El pez en el agua.

Nuestro análisis intenta demostrar la importancia de la figura paterna - principalmente en el sentido de su ausencia y de sus bruscas reapariciones - en la cristalización sintomática del tema de la fuga. Es por eso que una analogía con la posición fóbica, en relación al padre o a sus substitutos, nos ha parecido pertinente. Teniendo como pivot el análisis de la forma, del contexto y del contenido de su libro de memorias, este trabajo definiría así las bases de una contribución literaria de la obra de Vargas Llosa a la clinica de la fobia.

Palabras llave: Huida, figura paterna, fobia, psicopatología. 


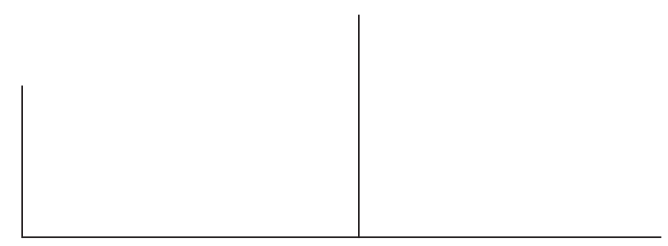

Sabemos que Mario Vargas Llosa pidió y obtuvo la nacionalidad española luego después de la publicación del controvertid o relato de memorias El pez en el agua. El cual sigue a su vez en el tiempo a la fascinante aventura en la que el escritor pretendió obtener el más alto cargo público de la república. Naturalmente, nos inquieta conocer los motivos y las razones que lo movieron a buscar algo que él, en principio, no necesitaba hacer. Nos parece que Mario Vargas Llosa no se encontraba realmente en la situación de demandar un asilo político para poder recomenzar su vida. Entonces, ¿por que, de dónde viene, a qué le sirve ese acto de transferencia de nacionalidad en ese momento de su vida?

¿Sería una respuesta a tal pregunta decir que Vargas Llosa renuncia al Perú como una venganza personal por la decepción que le causa la no satisfacción de su deseo de ser presidente? Pero si fuera así no veríamos su necesidad de escribir esas memorias como una novela (auto)crítica, ni la honestidad y el patriotismo que guiaron sus anhelos políticos En todo caso, se podría decir que de cierta forma fué él quien ganó las elecciones pues, al fin y al cabo, Fujimori, salvo ciertas medidas como la del autogolpe, ha puesto en práctica con eficiencia y rapidez la mayor parte de los capítulos esenciales del Plan de Gobierno del Frente Democrático (de Vargas Llosa). Se debe admitir entonces que, según un estilo y ritmo propios, Fujimori ha venido realizando el programa que Mario Vargas Llosa consideraba necesario para el Perú contemporáneo, esto es, según las palabras del escritor, abrir mercados, estimular la competencia y la iniciativa individual, no combatir la propiedad privada sino extenderla al mayor número, desestatizar nuestra economía y nuestra psicología, reemplazando la mentalidad rentista, que lo espera todo del Estado, por una moderna que confíe a la sociedad civil y al mercado la responsabilidad de la vida económica. ${ }^{1}$ 


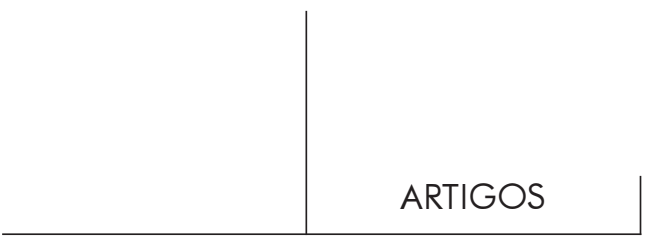

Mientras Fujimori, por un lado, ha moralizado el Estado al mismo tiempo que ha permitido que éste se fortalezca, se adelgace y se tecnifique ${ }^{2}$ (todavía según las palabras del programa de Vargas Llosa), por otro lado, ha pacificado el país, disminuyendo considerablemente la capacidad destructiva del terrorismo y evitando así el riesgo de una espiral que hubiera podido evoluir de la autodefensa a la guerra civil. Por todo eso, se puede constatar que, aunque es otra persona la que preside, el espíritu liberal del programa de Mario Vargas Llosa se ha efectivamente impuesto en la consciencia nacional.

\section{Sentido y denotación de El pez en el agua}

Digamos primero que el título de la obra parece muy simple a primera vista pero, a medida que se sigue la secuencia del relato, se vá volviendo cada vez más enigmático. Tenemos la impresión que para escojer el título no prevalecieron las fórmulas habituales del autor. En general, cuando Vargas Llosa intitula un libro Conversación en la catedral es porque en el relato se trata justamente de una larga conversación que tiene lugar en un bar llamado "La catedral". La ciudad y los perros; Los jefes, Los cachorros; Pantaleón y las visitadoras; La tía Julia y el escribidor; La señorita de Tacna; Historia de Mayta; ¿Quién mató a Palomino Molero?; La chunga; El hablador; Elogio de la madrastra son títulos que designan directamente a los personages del relato. Los que, dicho sea de paso, participan de la acción de más de un libro, como es el caso por ejemplo de La chunga o lituma. La casa verde y La guerra del fin del mundo denotan ya no los personages, sino el lugar o el evento central de la acción. Contrariamente a todos estos, El pez en el agua es un título metafórico. No denota directamente ni lo que ocurre ni el objeto de la acción.

Nos parece existir una relación muy estrecha entre la publicación del Pez en el agua y la demanda de la nacionalidad española, como si fuera ésta la respuesta en acto a lo que se quiso formular en el escrito pero que quedó velado. Es este llamado o mensaje al Otro que habría que decifrar, no sin pasar, claro está, por la identificación del objeto de la causa. Digamos, por el momento, que este mensaje representaría el epílogo de esas memorias tan presentes, escritas de tal manera que se pueden leer como una novela.

¿Por qué se pueden leer como una novela? En primer lugar, porque ellas están escritas como Vargas Llosa escribe sus novelas: intercalando los tiempos, de tal manera que los episodios no se suceden de forma cronológica linear sino concatenándose en dos o más series (crono)lógicas diferentes, lo que en la práctica 


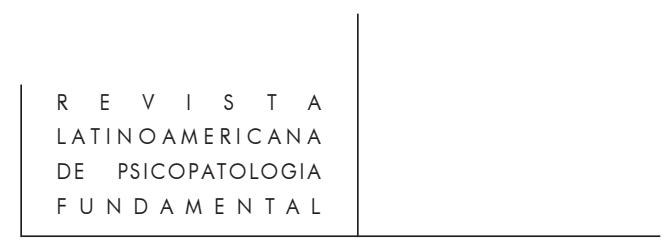

obliga a una lectura en vaivén. En segundo lugar, porque sabemos que, desde el inicio de su obra, el autor trabaja utilizando su propia biografía como material explícito para la creación narrativa. Además, esta verdad que constituye su biografía, implícita en las fantasías y mentiras artísticas, se presenta ella misma en El pez en el agua como si fuese el producto de una invención artística de una otra biografía aún más verdadera.

Sobre ésto, podemos decir, como lo formuló Merleau-Ponty en uno de sus cursos de los años 50 en el Collège de France, que no habría alternativa entre memoria de conservación (las representaciones pasivas de lo pasado) y memoria de construcción (la actividad consciente y voluntaria del recuerdo), pues la memoria verdadera se encontraría en la intersección de las dos. ${ }^{3}$ Siguiendo esta lógica, "escribir no sería solamente enunciar lo que se ha concebido" sino que sería una actividad que utiliza elementos que dan "a veces mas y a veces menos" de lo que la consciencia puso. Esto sería "la consecuencia de una serie de paradojas" como la "del autor y del hombre, [según la cual] lo que el hombre ha vivido, haciendo evidentemente la 1 substancia de su obra", necesita sin embargo, para "hacerse verdadera, de una preparación que fatalmente separa al hombre de los vivos"4. Sería, a nuestra manera de ver, la obra de Mario Vargas LLosa y sobre todo El pez en el agua, a la luz de sus obras precedentes, un excelente ejemplo de este "entre dos" donde la creación literaria se mantiene sutil pero tenazmente. Entre alienación y separación, entre recuerdo trabajado en el presente y olvidos pasados que pugnan por volver, surgen fantasías definidas por una lógica y que están conectadas al juego significante.

Mario Vargas Llosa no es un escritor romántico. Sus formulaciones van más bien a lo concreto, a lo real (aunque se presente deformado) y por ende a lo político. No hay en él un solo cuento que hable de amor sublimado; los que más se acercan, se basan en una imposibilidad real: Pichula Cuéllar ha sido castrado por Los cachorros ${ }^{5}$ en la realidad; o sobre una denegación oportuna y racionalista, como en La señorita de Tacna ${ }^{6}$ donde Belisario dice: "no es una historia de amor, no es una historia romántica. ¿Qué es, entonces? (Se encoge de hombros)". Hay aquí un impossible que se vuelca por sublimación idealizante a la escritura pero, para no confundirse demasiado con aquella, puntualiza con la negación. El otro escrito que huele a lo erótico, es más una cuestión de iniciación sexual, no solo simbólicamente edipiana sino que en lo real también. Hay aquí, pues, una substitución del real al simbólico.

3. M. Merleau-Ponty. Résumés de cours. Collége de France, 1952-1960. Paris, Gallimard, 1968, p. 71.

4. Idem, p. 23.

5. M. Vargas Llosa. Los jefes. Los cachorros. Madrid, Alianza Editorial, 1978.

6. M. Vargas Llosa. La señorita de Tacna. Barcelona, Seix Barral, 1981 y 1986. 


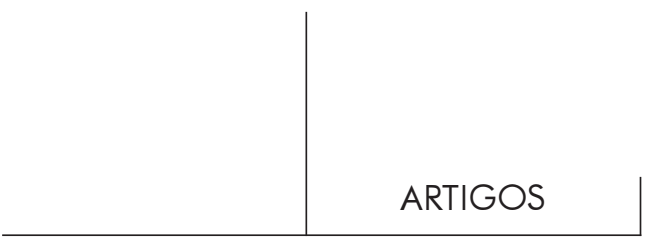

El amor, tal vez por eso, queda demasiado sobreentendido, como si no fuera necesario o como si costara mucho articularlo. La exhuberancia de las primeras formas del discurso escrito paga tal vez tributo a la negación del amor. Las mujeres se suceden. Son esas llamadas "visitadoras", mujeres de malvivir o, en su defecto, tías y madrastras. Esto es, objetos femeninos que pertenecen a otro, que son amadas por otro, a quienes no les cabe amar si se entregan. Así, cada vez que una relación de amor se vislumbra, nos encontramos fatalmente ante una situación triangular donde el simbólico es casi evacuado por el real. Y esto nos lleva a la figura del padre que sostiene de alguna manera estos objetos femeninos.

Sería tal vez exagerado decir que El pez es un libro de amor, pero hay algo ahí que incluye un amor conflictivo, fóbico y ambivalente al padre, como la búsqueda angustiada de un acceso al amor paterno, como una tentativa de ofrecer en sacrificio el amor al goce de la preevención. Fijémonos también que el personaje que sobresale, o que más impresiona, no es Alberto Fujimori ni Hernando de Soto ni el propio autor sino más bien el padre de Vargas Llosa. Ernesto Vargas tiene la peculiaridad de ser extremamente severo, excesivo en sus decisiones y, sobre todo, demasiado presente durante su ausencia y prácticamente ausente apesar de su presencia. Este padre nos parece tener la llave del enigma del pez en el agua y del traslado de este pez a otras aguas.

\section{Serie lógica de la huida en Vargas Llosa}

Partamos de la lógica que se muestra evidente en los relatos vargallosinos. Existe una serie de situaciones, fácilmente identificable en todos ellos, que se refiere a una misma actitud, o reacción, que es vivida o representada en contextos y momentos diferentes. Una serie que es una constante en los personages principales, los que además se presentan como figuras diferentes de una misma tipología, en varias o en casi todas las historias de nuestro escritor. Como núcleo fundamental de esta serie se define un razgo típico y esencial de la estructura paterna: la huída.

Ya sabemos ahora que "ese señor que era su papá" no estaba muerto sino que revivía con una fuerza extraña, como si del inconsciente brotara abruptamente una flor maldita. Este personaje inauguró su rol de padre huyendo de lo que de él mismo se estaba gestando en el vientre de un amor epistolar. Por diez años, y sin siquiera afrontar la experiencia de conocer a su hijo. Enseguida, las huídas se repetirían con la fuerza divina de la violencia del destino. En la repetición hay no sólo el tiempo que vuelve a ser vivido, como si el pasado volviera al presente, sino hay también una convergencia, o complicidad, del sufrimiento con el placer hasta que se convierte en un modo de ser, es decir en una estructura en donde el deseo está implicado hasta la raíces más profundas. 


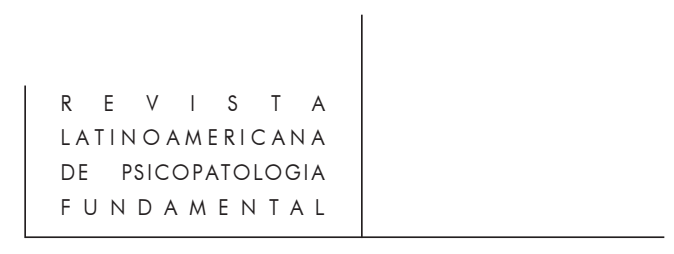

En Conversación en la catedral ${ }^{7}$, Santiago prefiere eclipsarse frente a la confessión que le hace Aída de la declaración de amor de Jacobo a ésta. Aparte de que se concretiza plenamente la consciencia del triángulo amoroso, existe en este episodio una huída sintomática en la que Santiago sacrifica su mudo amor por Aída, al no aceptar el reto apenas camuflado y resignándose a renunciar antes que enfrentar a quien podríamos considerar como el substituto del padre. Precavido ante el peligro, antes que culpable, Santiago se dicta a sí mismo su consciencia fóbica:

Era otro el que hablaba, piensa, no tú. La voz un poco más firme ahora, más natural, Zavalita: no era él, no podía ser é1. Comprendía, explicaba, aconsejaba desde una altura neutral y pensaba no soy yo. Él era algo chiquito y maltratado, algo que se encogía bajo esa voz, algo que se escabullía y corría y huía. ${ }^{8}$

Luego, en Tia Julia y el escribidor ese matrimonio simbólicamente incestuoso se impuso a Marito como algo "irreflexivo" y radical, donde la anticipación de la realización del deseo de ser grande (de ser hombre) lo sobrepuso a las dificultades inevitables de lo ilegal. Pero esta transgressión iba en el sentido del padre, seguía la versión del padre que era la consagración, o la prueba al menos, de la virilidad del hijo. "Después de todo, casarse es un acto de hombría, señor Vargas. Una afirmación de la virilidad. No es tan terrible, pues" ${ }^{10}$; estas palabras logran tranquilizar al padre y le hacen tolerar el matrimonio. Además, "tres cosas" fascinaban a Marito en el padre: "lo que decía, la austeridad de su vida enteramente consagrada a una obsesión, y su capacidad de trabajo"11. "Tres cosas" simbolizan también en la clínica freudiana la presencia sexual masculina y en este caso, las tres cualidades no son menos viriles. La fascinación puede ser también una consecuencia del horror o del terror. La fascinación de lo impossible del carácter paterno dió rienda suelta a la respuesta prematura del hijo, en la cual repitiría el acto de la huída:

... casarme con la tía Julia y poner a la familia ante un hecho legal consumado al que tendrían que resignarse, quisiérando o no. Como faltaban pocos días y la resistencia de los munícipes limeños era tan tenaz, esa primera opción se volvía cada instante más utópica. La segunda era huir con la tía Julia al extranjero. ${ }^{12}$

7. M. Vargas Llosa. Conversación en la catedral. Barcelona, Seix Barral, 1969 y 1989, p. 124 y ss.

8. Idem, pp. 126-127.

9. M. Vargas Llosa. La tía Julia ye el escribidor. Barcelona, Seix Barral , 1977 y 1990, p. 319.

10. M. Vargas Llosa. El pez en el agua. Op. cit., p. 335.

11. M. Vargas Llosa. La tía Julia ye el escribidor. Op. cit. , p. 156.

12. ldem, p. 331. 


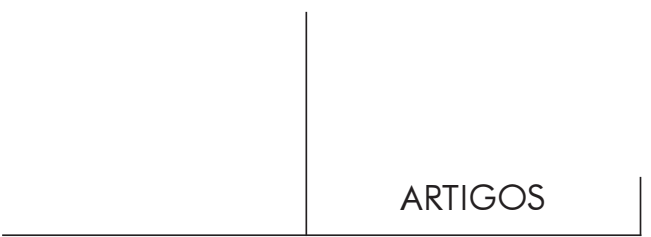

Hay en Vargas Llosa una multiplicidad de modalidades de la huída, desde los escritos más tempranos hasta los más recientes. En Los cachorros se desarrolla, vehemente, la angustia de castración de un pequeño sujeto atolondrado, hasta lo irremediable causado por un animal enloquecido. No está demás citar uno de los adolescentes en el preámbulo del cuento: "si se escapa [el perro] hay que quedarse quietos, los daneses sólo mordían cuando olían que les tienes miedo, ¿quién te lo dijo?, mi viejo"13. Es como si detrás de la furia de Judas, el perro, estuviera el deseo del padre. En La ciudad y los perros tenemos la narración detallada de lo que son las huídas intermitentes y parciales, altamente productoras de adrenalina, de los "locos" del Colegio Militar Leoncio Prado ${ }^{14}$. En El hablador se trata de la historia de una huída absoluta, de cultura, de sociedad, de ambiente físico, de identidad, de rol social... De esta partida radical, Vargas Llosa dice:

Ese género de decisión, la de los santos y los locos, no se publicita. Se va forjando poco a poco en los repliegues del espíritu, al sesgo de la propia razón y al resguardo de miradas indiscretas, sin someterla a la aprobación de los otros - que jamás la concederían - hasta que se pone en práctica. Me imagino que en el curso de ese proceso - la forja del proyecto y su mutación en acto - el santo, iluminado o loco, se va aislando, amurallando en una soledad que los demás no están en condiciones de hollar. ${ }^{15}$

Al final de la historia, podemos verificar que "el hecho decisivo para el gran paso fue, sin duda, la muerte de Don Salomón [su padre], la única persona a la que Saúl estaba atado y a la que sentía obligación de dar cuenta de su vida" "16. Así, una vez el padre muerto, "es evidente que se fue de Lima con la intención de no volver y de ser otro para siempre jamás"17. Lo interesante del caso es la equivalencia de la decisión del "hablador" con la actual de Vargas Llosa:

... que mi amigo Saúl Zuratas renunciara a ser todo lo que era y hubiera podido llegar a ser [... ] es algo que, de tiempo en tiempo, me vuelve a la memoria y [...] desboca mi corazón con más fuerza que lo hayan hecho nunca el miedo o el amor. ${ }^{18}$

13. M. Vargas Llosa. Los jefes. Los cachorros. Op. cit., p. 106.

14. M. Vargas Llosa. La ciudad y los perros. Barcelona, Seix Barral, 1987 y 1989, pp. 268-269.

15. M. Vargas Llosa. El hablador. Barcelona, Seix Barral, 1987, p. 36.

16. Idem, p. 232.

17. Idem.

18. Idem, p. 234. 


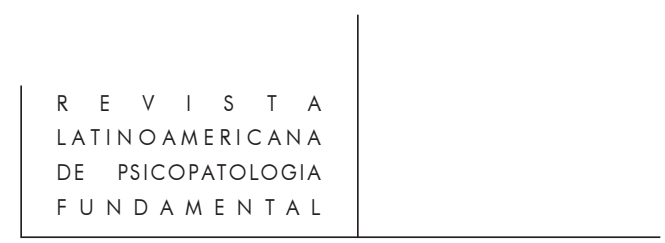

\section{Serie lógica de la huída fóbica}

Según el análisis freudiano, todas las modalidades de la huída normal o patológica, o sea justificadas o injustificadas por un evento de la realidad presente, se basan en un deseo de prevención.

Del análisis de Juanito y del Hombre de los Lobos podemos extraer una serie lógica de eventos reales o fantasmáticos, deformados forzosamente por la fantasía neurótica. En primer lugar, debe señalarse la posición singular del padre, el cual no llega a llenar completamente el rol que le estaría destinado por su categoría de progenitor. La relación que el fóbico establece con el padre está dominada por una antítesis de deseo y de angustia, de ausencia y de percepción inesperada. Observamos "una actitud libidinosa del sujeto con respecto a su padre, acompañada de miedo al mismo"19. A veces, un animal puede jugar el papel de substituto de una exigencia amorosa al padre, idealizada y no satisfecha por causa de su ausencia. Una ausencia que no puede ser exactamente física sino temporal (ausencia en el presente, ausencia apesar de la presencia) o estructural (el padre puede presentarse como demasiado algo, o no suficientemente aquello). Esta ausencia puede paradójicamente alternar con bruscas apariciones paternas, lo que indica que puede existir una conexión importante entre la angustia y la percepción (brusca e inesperada) de este objeto, temido y deseado al mismo tiempo. En el estudio sobre "Inhibición, síntoma y angustia", Freud nos dice a este respecto que

... la angustia de la fobia es, en efecto, facultativa. No aparece sino ante la percepción de su objeto, cosa perfectamente justificada, puesto que sólo entonces existe el peligro. De un padre ausente no puede temerse la castración. Ahora bien; el padre no puede ser suprimido y aparece ante el sujeto cuando quiere..$^{20}$

En segundo lugar, encontramos un amor a la madre, transformado más bien en identificación a ella, lo que en el Hombre de los Lobos se desarrolla teniendo como tema de fondo el erotismo anal ${ }^{21}$. En el caso de Juanito, hay toda una producción teórica y un descubrimiento o al menos curiosidad en relación con el origen de los niños. En esta epistemología infantil, el erotismo y la actividad anal materna representan el tema central. La madre de este fóbico es pues sólo un instrumento para el descubrimiento científico del origen del "mojón" (ese pedazo inútil, excremento o niño, que nace supuestamente por el ano). En el caso del fóbico, la madre sirve pues como campo de preparación de la angustia a partir de la teoría

19. S. Freud. "Metapsicología”, Obras Completas, vol. I. Madrid, Biblioteca Nueva, 1943, p. 1061. 20. S. Freud. "Inhibición, síntoma y angustia”, $O$. C., vol. I. Op. cit., pp. 1253-1254.

21. S. Freud "Una neurosis infantil”, Historiales Clínicos. O. C., vol. II. Op. cit., p. 728. 


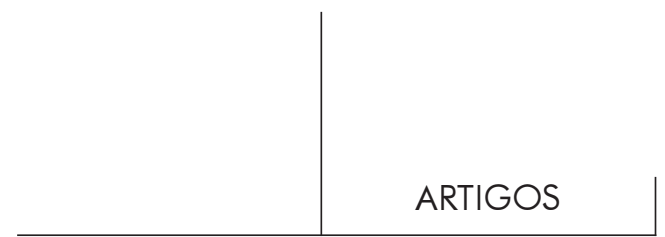

cloacal. Así, en el momento final de la formación del síntoma se nota un declinio del interés por la madre que va hasta la liquidación del amor por ésta.

En tercer lugar, habría que decir que la formación del síntoma tiene más bien como punto central esa misma relación con la madre, pero revertida como actitud femenina con respecto al padre ${ }^{22}$, lo que supone un mixto de sadismo y masoquismo, de idealización y de amor paternos. Así, el Hombre de los Lobos, "en el sadismo mantenía su primitiva identificación con el padre, y en el masoquismo le elegía como objeto sexual" 23 . En la simple idealización, este sistema puede operar gracias a la fantasía neurótica antitética (histeria y obsesión), pero para la formación del síntoma fóbico se necesita aún la presencia de la percepción, siendo la aparición inesperada del padre una de las formas más elaboradas de esta percepción. En la Metapsicología, Freud trata de dos condiciones para el surgimiento de la angustia.

Primeramente, cuando el impulso erótico reprimido experimenta una intensificación, y en segundo lugar, cuando es percibido el animal [objeto fóbico, objeto substituto del padre] productor de angustia. ${ }^{24}$

En la substitución fóbica, la angustia permanece apesar del desplazamiento de objeto y el sujeto se vuelve solamente ahora sensible a la percepción de ese nuevo objeto, "como si no entrañara inclinación ninguna hacia su padre, [como si] se hubiese libertado de él en absoluto" 25 . En ese sentido, el elemento latente, reprimido y fundamental de la percepción de la amenaza es el padre y no el objeto-substituto manifiesto.

En cuarto lugar, hay que tratar del masoquismo de la madre considerándolo como el elemento generador de la amenaza paterna. En la teoría sexual infantil, si la madre asume una postura cualquiera de sufrimiento, de submisión o de víctima del padre, ésto es asimilado por el niño a su complemento contrario: el deseo de amenaza, de dominio o de agresión de la parte de ese padre. La amenaza, que el masoquismo materno coinduce a teorizar en el pequeño sujeto, lo lleva a crear o materializar, intensificándola al máximo, la figura de un padre castrador.

En quinto lugar, tenemos entonces una angustia de castración reeditada. Es curioso percibir que, partiendo de una figura paterna de ausencia, según la cual el padre puede por ejemplo ser considerado como muerto, se llegue, por intermedio de una aparición o reaparición del mismo, a una presencia masiva y excesiva de la

22. S. Freud. "Inhibición, síntoma y angustia”. O. C., vol. I. Op. cit., p. 1253.

23. S. Freud “Una neurosis infantil”, Historiales Clínicos. O. C., vol. II. Op. cit., p. 721.

24. S. Freud. "Metapsicología”, O. C., vol. I. Op. cit., p. 1071.

25. Idem. 


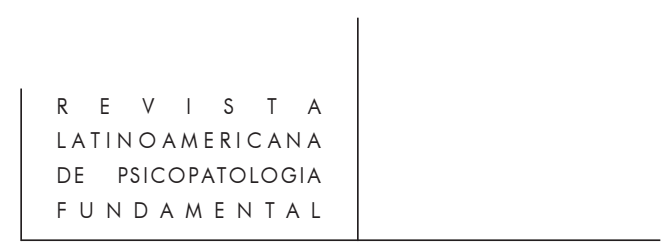

amenaza castradora. Es como si la angustia de castración hubiera quedado en los primeros tiempos insatisfecha, en tanto que operación inacabada o incumplida, justamente por falta de presencia de la figura paterna. A ese propósito, Lacan señala en su Seminario sobre La transferencia que "lo que es remarcable en la observación de Juanito, es a la vez la carencia y la presencia del padre. Carencia bajo la forma del padre real, presencia bajo la forma del padre simbólico, entrometido"26.

Finalmente, la percepción de la amenaza, convirtiéndose en angustia reeditada, hace sonar la señal de alarma necesaria para evitar el peligro. Como signo de peligro, la angustia aspira a satisfacer un deseo de evitamiento y de protección del objeto fálico amenazado. Las tentativas de evitamiento pueden ser de varias modalidades, según el grado del peligro o según la capacidad de soportar el peligro o el riesgo, pero en el fondo ellas difieren del enfrentamiento histérico en el sentido en que el evitamiento fóbico es la manifestación de una tendencia a la fuga de la fuente de peligro. Si la provocación histérica sólo acaba su relación al objeto con la fuga cuando el placer narcisista alcanza su máximo, al mismo tiempo que el peligro sus límites, en la fuga fóbica no encontramos esta dualidad de provocación y fuga sino, más bien, una actitud angustiosa creciente que se predispone a huir antes del acto supuestamente peligroso. Podríamos decir que el fóbico se previene de lo que el histérico goza. Antes de todo enfrentamiento directo, antes de toda provocación inmediata o sostenida, antes de tener que remediar una pérdida evitable el fóbico actúa (en el sentido de modo de ser en la vida, así como en el de representar un papel "teatral") renunciando a la posibilidad de percepción, de contacto o de afecto con el objeto escogido para representar un padre demasiado amenazador y entrometido.

Lo que el fóbico tiende a preservar es un significante amenazado que sirve para todo. Según Lacan, "la forma más radical de neurosis" tenta preservar y sostenir el deseo "bajo la forma de la angustia" 27 . La lucha del fóbico se manifiesta "contra la amenaza de la desaparición del deseo" 28 , representada por un objeto que se substituye al padre entrometido y que tiene como función aquella del símbolo fálico. Este significante fálico representa y dá la razón del deseo, en el sentido en que el falo es el ser del lenguaje y no el ser de los objetos. En ese elemento primordial del lenguaje se afirma el deseo como condición absoluta: no exactamente como "deseo de" sino más bien como "causa de deseo". Y es en relación al significante primordial que el sujeto fóbico va a construir su síntoma. Si la angustia de castración se formula

26. J. Lacan. Le Séminaire. Livre VIII - Le Transfert (1960-1961). Texte établi par J.-A. Miller. Paris, Seuil, 1991, p. 425.

27. Idem, p. 425.

28. J. Lacan. Ecrits. Paris, Seuil, 1966, p. 682. 


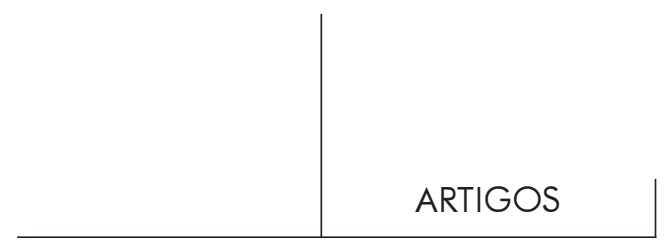

en el histérico como un miedo a perder el objeto de amor y en la obsesión se traduce por un miedo frente al Super-yo, en el sujeto fóbico el problema se sitúa en un miedo a perder el deseo, o mejor dicho, en un miedo a perder lo que sostiene y causa el deseo. En efecto, para Lacan, la fobia

... es el signo luminoso que aparece para advertir que uno circula con la reserva de libido. Con ésta se puede circular todavía un cierto tiempo. Eso es lo que la fobia quiere decir y es por esta razón que su soporte es elfalo como significante. ${ }^{29}$

En el relato del Pez en el agua, así como en las otras narraciones vargallosinas, la serie lógica que interviene en la formación de la huída fóbica está presente. Al inicio, el pequeño vive creyendo que su padre está en el cielo, lo idealiza al punto de impedirle de escoger un otro padre, entre la gran cantidad de tíos. El padre ausente, " muerto", es fuente de rectitud moral y amor a la idea del ser pero, justamente por esa ausencia tan presente, le impide dejar de tener muchos padres que no lo son. Pues son sólo tíos, abuelos, o los dos. Luego está el gran amor por la madre, bajo la forma de un monopolio erótico, sublimado en la pasión de la inocencia. Creador ya, sin embargo, de una ansiedad curiosa. En seguida, la reaparición de ese torbellino llamado Ernesto, padre derrocado por otros substitutos pero no lo suficientemente muerto para no causar sentimientos ambivalentes y pánico (más que culpabilidad) frente a esos sentimientos antitéticos. De un momento a otro, ¡que padre más presente! Y al mismo tiempo, qué falta de discernimiento, de equilibrio, de estabilidad, de relativismo en su educación, en su demanda de cariño y de respeto. De un momento donde el padre no existe, pasamos a otro donde lo que existe es un padre tremendamente unilateral. Lo impresionante no son exactamente sus puniciones, que sólo valen como modelo o ejemplo, sino sus amenazas. Es asíque el niño pasa a angustiarse más de la amenaza que de la punición, más del grito que del azote, más del peligro que de lo irremediable, más del gesto que del golpe. Angustia del anteojo, no del ojo, diría Vallejo. Así, de manera ineluctable, el universo simbólico se va reduciendo a un solo significante que soporta la función del objeto fóbico, la fuente del deseo y el carácter amenazador en la percepción del objeto.

En la época de la cristalización del síntoma, la angustia va suplantando cada vez más la aparición del deseo y lo intensifica en su posición de acción preventiva. Para eso, la repetición y la constancia del masoquismo materno son elementos importantes. La madre participa activamente, como cómplice, en la actitud fugitiva y exagerada del padre, dándole una tonalidad de placer, de utilidad y de responsabilidad moral. La exhuberancia del caso es que el masoquismo materno conlleva a una liquidación del interés erótico por la madre y, al mismo tiempo, por 


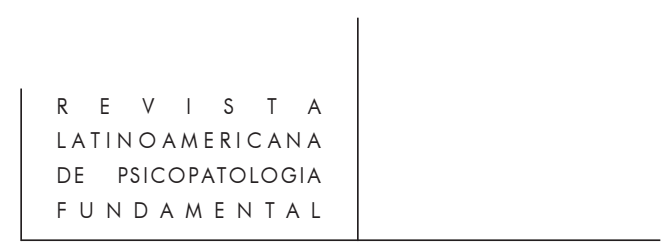

medio de una idealización de la amenaza paterna, a un acréscimo del amor y del miedo por el padre. Combinando las dos vías, la del masoquismo matemo y la de la extrema idealización del padre ausente, llegamos a un resultado semejante al del síntoma fóbico: la amenaza paterna reedita la angustia de castración de una manera desplazada. A partir de la formación del síntoma, ya no se huye sólo del padre sino también, y sobretodo, de otros objetos que lo representan.

Debemos decir también que el síntoma fóbico tiene su utilidad pues se presenta como una serie de tentativas de protegerse contra el peligro, por medio de un evitamiento, o sea por fuga, del objeto amenazador. En ese sentido, según Freud,

... el mecanismo de la fobia presta, como medio de defensa, excelentes servicios y muestra una gran tendencia a la estabilidad. Con frecuencia, pero no necesariamente, surge una continuación de la lucha defensiva, dirigida entonces contra el síntoma. ${ }^{30}$

En Vargas Llosa vemos que el síntoma fóbico es, no solamente condición de una sólida fidelidad, firmeza y estabilidad, sino también objeto de una nueva defensa: una defensa contra el síntoma mismo, aunque esta última se percibe menos claramente.

Veamos ahora los pasos posibles que se encuentran entre la repetición del síntoma y la defensa contra este último. Si la repetición del síntoma va en el sentido de la fuga, a cada ocasión en que la percepción señala el objeto y apela a la angustia, la defensa contra éste irá en el sentido de un enfrentamiento por ejemplo, es decir en una lucha angustiante contra el objeto substituto.

En las elecciones peruanas para la Presidencia en 1990, se verifica la existencia de elementos tales que podrían componer (y que podrían haber desencadenado) una serie lógica de fobia en Vargas Llosa. Primero, en vez y lugar de un padre ausente, lo que se sabía y verificaba a cada día en los sondeos de opinión es que, durante un largo tiempo, no había quien rivalizara prácticamente con Vargas Llosa. De hecho, en el inicio de la campañia el sujeto se encuentra, en relación a su objeto de deseo y de goce, en una situación en la que el rival queda ausente. Exactamente, la misma posición del padre ausente, supuestamente muerto o simplemente idealizado en la distancia del tiempo.

Segundo, y como consecuencia del primer punto, se presenta un amor identificatorio a la patria, a la madre patria podríamos decir. O sea que la patria lo ama, él lucha contra el terrorismo y, así, va a "salvar" al país (a la madre).

Tercero, el paraíso teórico se rompe. De las tinieblas profundas de ese ser materno, surge inesperadamente el rival que se creía ausente. Lo que aparentemente faltaba en el real vuelve a presentarse allí mismo donde se le creía ausente. La 


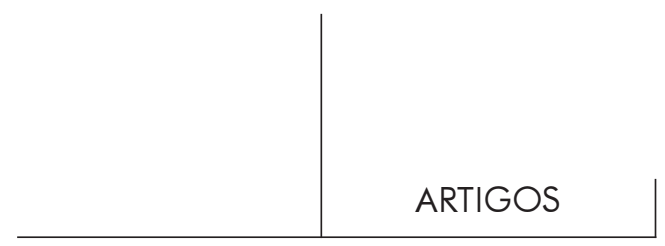

percepción de esa aparición se va volviendo rápidamente amenazadora pero la consciencia parece sobreponerse a ese contratiempo. El yo lo considera como tal: como contratiempo. No hay tiempo que perder por eso. Lo importante es continuar con el programa de la campaña y no seguir los últimos consejos que proponen más bien un enfrentamiento.

Cuarto, la amenaza se hace irreducible insuperable. Es el producto del masoquismo latente y conocido de la patria peruana, que busca sufrir para encontrar valor. Los electores habían querido votar por Vargas Llosa pero el padre real había sido más fuerte por causa del propio masoquismo de la opinión pública.

Quinto, de la angustia de perder las elecciones se vive luego la angustia de perder la nacionalidad, amenaza simbólica. Es como si Ernesto, padre, rival y verdugo imposible, estuviera nuevamente demasiado presente.

Finalmente, antes de tener que perder el deseo por esa gente, por ese país exagerado - en el cual solo un extranjero se puede volver profeta, rico e incluso "loco de sus balcones" 31 - el síntoma de la huída se impone, nuevamente, para preservar el deseo.

31. M. Vargas Llosa. El loco de los balcones. Barcelona, Seix Barral, 1993. El personaje principal es un italiano que vive en el Perú. Al final de una digna lucha por volver a ese tiempo pasado, que siempre fue mejor, decide suicidarse. Apesar de esta decisión, la pequeña historia parece ya una forma de luchar contra el síntoma de la huída.

Mario Vargas Llosa habla varios idiomas. Debe saber también el italiano pues ha pasado temporadas en Italia. Pongamos entonces como hipótesis de sus formaciones inconscientes la siguiente: si dividimos la palabra FUJIMORI en dos partes conteniendo dos sílabas cada una y si agregamos, a las palabras así obtenidas, la sílaba RE, tendríamos la siguiente composición fonética italiana:

$$
\begin{array}{ll}
\text { FUJIMORI } & \\
\text { FUJI } & \text { MORI } \\
\text { FUJI-RE } & \text { MORI-RE }
\end{array}
$$

Lo que querría decir: huir y morir; huir o morir. 


\section{Bibliografia}

Freud, S. "Metapsicologia". Obras Completas, vol. I. Madrid, Biblioteca Nueva, 1943. "Inhibición, sintoma y angustia". $O$. C., vol. I. Op. cit.

"Una neurosis infantil", Historiales Clínicos. $O$. C., vol. Il. Op. cit.

LACAN, J. Le Séminaire. Livre IV - La Relation d'objet. (1956-1957). Texte établi par J.-A. Miller. Paris, Seuil, 1994.

Le Séminaire. Livre VIII - Le Transfert (1960-1961). Texte établi par J.-A. Miller.

Paris, Seuil, 1991. Ecrits. Paris, Seuil, 1966

Merleau-Ponty, M. Résumés de cours. Collège de France, 1952-1960. Paris, Gallimard, 1968.

Rodriguez Rea, M.A., Tras las huellas de un crítico: Mario Vargas Llosa, 1954-1959.

Lima, Pontificia Universidad Católica del Perú, Fondo Editorial, 1996.

SetTi, Ricardo A. Conversas com Vargas Llosa. São Paulo, Brasiliense, 1986.

VArgas Llosa, M. Los jefes (1959). Los cachorros (1967). Madrid, Alianza Editorial, 1978. La ciudad y los perros (1963). Barcelona, Seix Barral, 1987 y 1989.

La casa verde (1965). Barcelona, Seix Barral, 1988.

Conversación en la catedral (1969). Barcelona, Seix Barral, 1989.

122 Historia secreta de una novela. Barcelona, Tusquets Editor, 1971.

Pantaleón y las visitadoras (1973). Barcelona, Seix Barral, 1991.

La orgia perpetua: Flaubert y “Madame Bovary”. Barcelona, Seix Barral, 1975.

La tia Julia y el escribidor. Barcelona, Seix Barral, 1977 y 1990.

La señorita de Tacna (1981). Barcelona, Seix Barral, 1986.

La guerra del fin del mundo. Barcelona, Seix Barral, 1981.

Historia de Mayta. Barcelona, Seix Barral, 1984.

La chunga. Barcelona, Seix Barral, 1986.

¿Quién mató a Palomino Molero? Barcelona, Seix Barral, 1986.

E1 hablador. Barcelona, Seix Barral, 1987.

Elogio de la madrastra (1988). Barcelona, Tusquets Ed., 1989.

La verdad de las mentiras. Barcelona, Seix Barral, 1990.

Carta de batalla por Tirant lo Blanc (1969). Barcelona, Seix Barral, 1991.

El pez en el agua. Barcelona, Seix Barral, 1993.

El loco de los balcones. Barcelona, Seix Barral, 1993.

Lituma en los Andes. Barcelona, Planeta, 1993.

Desaflos a la libertad. Madrid, El Pais/Aguilar, 1994. 


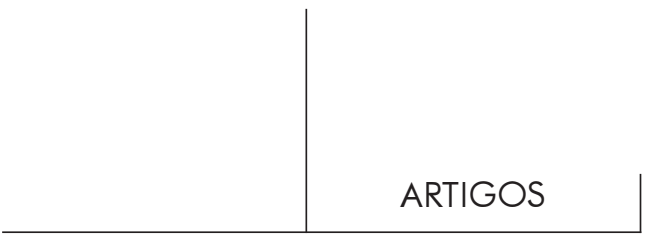

Resumos

Este artigo trata de pôr em perspectiva a maior parte dos romances de Mario Vargas Llosa em função do tema da fuga, partindo do fato de que ele pediu a nacionalidade espanhola logo depois de perder as eleições para a Presidência do Peru e de escrever El pez en el agua.

A nossa análise tem a intenção de demonstrar a importância da figura paterna principalmente no sentido da sua ausência e de suas bruscas reaparições - na cristalização sintomática do tema da fuga. É nesse sentido que uma analogia com a posição fóbica, em ralação ao pai ou a seus substitutos, nos pareceu pertinente. Tendo como pivô a análise da forma, do contexto e do conteúdo do seu livro de memórias, este trabalho definiria assim as bases de uma contribuição literária da obra de Vargas Llosa à clínica da fobia.

Palavras-chave: Fuga, figura paterna, fobia, psicopatologia.

Il s'agit d'une mise en perspective de la plupart des romans de Mario Vargas Llosa en fonction du thème de la fuite, en partant du fait qu'il a demandé la nationalité Espagnole juste après avoir perdu les élections pour la Présidence du Pérou et d'avoir écrit Un poisson dans l'eau.

Notre analyse tente démontrer l'importance de la figure paternelle principalement son absence et ses brusques réapparitions - pour la cristallisation symptomatique du thème de la fuite. Dans ce sens, une analogie avec la position phobique, en relation au père ou à ses substituts, nous a semblé pertinente. Ayant comme pivot l'analyse de la forme, du contexte et du contenu de son livre de mémoires, le présent travail poserait ainsi les bases pour une contribution littéraire de 1'oeuvre de Vargas Llosa à la clinique de la phobie.

Mots clés: Fuite, figure paternelle, phobie, psychopathologie.

The purpose of this work is to consider the narrative of nobels in the literary work of Mario Vargas Llosa concerning the subject of escape, starting from his own experience when he asked for the Spanish nationality immediatly after he lost his election as to President of Peru and afterwards when he wrote El Pez en el Agua.

Our study wants to demonstrate the importance of the paternal figure - principally in the sense of this absence and his suddenly reappearances - in symptomatical cryztallization about escapes. Therefore, we beleive pertaining an analogy against the phobia position, in relation with the father or his substitutes. Considering as a pivot the analysis of his style, context and the content of his book of memories, the present work defines in this manner the basis of a literary contribution of the narrative of Vargas Llosa to the clinical of the phobia.

Key words: Scape, father image, phobia, psychopathology. 